\title{
Đánh giá những nhân tố gây ảnh hưởng đến chất lượng tường vây, tường chắn đất trong các dự án xây dựng ở Việt Nam
}

\author{
Nguyễn Dương Đăng Khoa ${ }^{1}$, Đỗ Tiến $S \tilde{y}^{1}$, Phạm Thanh Hải ${ }^{1}$ \\ ${ }^{1}$ Khoa Kỹ Thuật Xây Dựng, Trường Đại học Bách Khoa TP.HCM, Đại học Quốc gia Thành phố Hồ Chí Minh
}

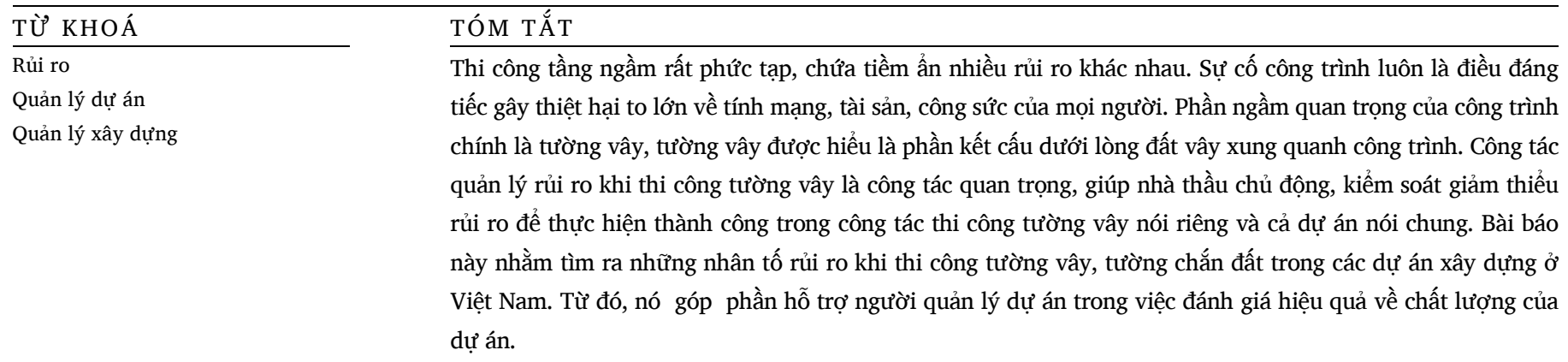

\section{KEYWORDS}

Risk

Project management

Construction management

\begin{abstract}
Construction of underground floors is very complicated, containing many potential risks. Construction incidents are always regrettable, causing great damage to people's lives, property and efforts. The important underground part of the work is the diaphragm wall, the diaphragm wall is understood as the underground structure surrounding the work. Risk management in diaphragm wall construction is an important task, helping the contractor to be proactive, control and minimize risks to successfully implement the diaphragm wall construction in particular and the project in general. This article aims to find out the risk factors when constructing diaphragm wall, earth retaining wall in construction projects in Vietnam. From there, it contributes to supporting the project manager in evaluating the effectiveness of the project's quality.
\end{abstract}

\section{1. Đặt vấnđề}

Xu thế tất yếu là khai thác và sử dụng không gian dưới mặt đất có hiệu quả đối với khu đô thị hiện đại như hệ thống hầm (hầm thủ thiêm), tàu điện ngầm và các tầng hầm trong cao ốc. Mật độ dân số ngày càng đông, riêng thành phố Hồ Chí Minh được thống kê năm 2019 con số tăng lên 8993082 người cũng là nơi có mật độ dân số cao nhất Việt Nam (nguồn Wekipedia). Mỗi năm con số sẽ tiếp tục tăng thêm, tốc độ phát triển nóng tạo nên áp lực về giao thông, đô thị, hạ tầng....Chính vì vậy đòi hỏi việc phát triển đô thị hạ tầng theo hướng phát triển về chiều sâu lẫn chiều cao để tăng diện tích sử dụng. Phần ngầm quan trọng của công trình chính là tường vây, tường vây được hiểu là phần kết cấu dưới lòng đất vây xung quanh công trình. Có rất nhiều nghiên cứu trên các tạp chí khoa học, tạp chí xây dựng, các luận văn thạc sỹ nói về vấn đề tầng hầm nhà cao tầng, quản lý rủi ro khi thi công tầng hầm nhưng chưa có nghiên cứu cụ thể nào đề cập đến những rủi ro về tường vây, tường chắn đất. Tường vây, tường chắn đất là một trong những vấn đề cơ bản khi thi công tầng hầm đó là giữ ổn định hố đào khi thi công, tùy vào ba yếu tố chính là điều kiện địa chất, mặt bằng thi công, chiều sâu hố đào mà ta chọn được phương pháp phù hợp, phương pháp thi công Topdown, Semi- Topdown nhằm giải quyết vấn đề tiến độ chất lượng hố đào sâu. Bài báo này nghiên cứu về tường vây, tường chắn đất và xây dựng quy trình thi công và đánh giá những rủi ro tiềm ẩn.

2. Tổng quan về những nghiên cứu có liên quan đến chất lượng tường vây, tường chắn đất trong các dự án xây dựng ở Việt Nam

Một nghiên cứu của Đỗ Công Hoan (2020) về Xây dựng ảnh tiêu chí lựa chọn đơn vị thi công tường vây và khoan nhồi cho các dự án cao tầng tại thành phố Hồ Chí Minh [9], cũng đã Xây dựng mô hình ANP để tính toán trọng số của các tiêu chí nhằm hỗ trợ cho các bên liên quan có cái nhìn và sự lựa chọn đơn vị thi công tường vây và cọc khoan nhồi phù hợp trong quá trình hỗ trợ ra quyết định lựa chọn ở giai đoạn kiểm tra hồ sơ kỹ thuật trong hồ sơ dự thầu của các đơn vị thi công.

Nguyễn Minh Trực (2011) về Quản lý rủi ro trong quá trình thi công tầng hầm ở các dự án nhà cao tầng [11], đã sử dụng công cụ WBS và $\mathrm{RBS}$ để quản lý các công việc và quản lý các rủi ro và sử dụng các công cụ thống kê SPSS để phân tích các yếu tố rủi ro và trình bày một số phương pháp đánh giá mức độ rủi ro nhằm đưa ra phương án ứng phó rủi ro thích hợp, qua đây cũng cho thấy vấn đề rủi ro không phải nằm ở các yếu tố kĩ thuật mà chủ yếu nằm ở vấn đề quản lý. Từ đó, các chủ đầu tư, nhà quản lý dự án cần có những nhận thức về tầm quan trọng của những công tác này. 


\section{Phương pháp nghiên cứu}

Từ những nghiên cứu tương tự trên thế giới và các báo cáo trong nước tác giả đã tổng hợp một danh sách các nhân tố rủi ro. Đểchắc chắn các nhân tố này là phù hợp với điều kiện Việt Nam hiện tại, chúng đã được khảo sát, xem xét bởi nhóm chuyên gia thứ nhất gồm 5 thành viên. Đây là những cán bộ đang làm việc trong ban quản lý dự án, tư vấn giám sát, nhà thầu của các dự án nhà cao tầng có tầng hầm đã có nhiều năm kinh nghiệm và đang giữ những vai trò quan trọng trong công ty, đơn vị. Kết quả, nhóm chuyên gia và tác giả đã thống nhất 32 nhân tố rủi ro với đề xuất 06 nhóm rủi ro chính. Các nhân tố được sử dụng để xây dựng bảng câu hỏi khảo sát thử nghiệm. Bảng này được tiếp tục được gửi đến từ một nhóm chuyên gia gồm 15 người, hiện làm việc trong các dự án đầu tư xây dựng tại Tp. Hồ Chí Minh và các khu vực lân cận. Nhóm chuyên gia gồm 6 người làm việc ở vị trí chuyên viên, 7 người ở vị trí trưởng phòng/ phó phòng, 2 người ở vị trí Giám đốc/ phó Giám đốc. Quá trình khảo sát, tác giả đã nhận dạng được 37 nhân tố rủi ro, gồm 6 nhóm chính đề xuấtphù hợp với điều kiện Việt Nam hiện tại để thiết kế bảng câu hỏi khảo sát chính thức phục vụ cho công tác khảo sát đại trà được thểhiện ở Bảng 1. Trong giai đoạn khảo sát chính thức, vì tính chất đặc thù, nghiên cứu ưu tiên thực hiện phương pháp gửi bảng câu hỏi trực tiếp và một phần thông qua ứng dụng trực tuyến. Sau gần hai tháng tiến hành khảo sát, tác giả thu được tổng cộng 165 phản hồi và chuẩn bị cho quá trình phân tích dữ liệu tiếp theo.

\section{Phân tích dữ liệu}

Kết quả thu được tổng cộng 165 bảng câu hỏi hợp lệ, sau đó tiến hành tổng hợp giá trị trung bình và xếp hạng của các nhân tố như Bảng 1.

\section{Bảng 1.}

Bảng xếp hạng các nhân tố rủi ro theo các biến quan sát (theo mức độ tác động đến chất lượng tường vây, tường chắn đất trong các dự án xây dựng ở VN).

\begin{tabular}{|c|l|c|}
\hline Hạng & \multicolumn{1}{|c|}{ Nhân tố rủi ro } & $\begin{array}{c}\text { Trung } \\
\text { bình }\end{array}$ \\
\hline 1 & $\begin{array}{l}\text { Hạn chế về năng lực của đội ngũ cán bộ như ban } \\
\text { quản lý dự án, tư vấn, nhà thầu về biện pháp thi } \\
\text { công tường vây }\end{array}$ & 4,36 \\
\hline 2 & Phương án thiết kế tường vây không hợp lý & 4,36 \\
\hline 3 & $\begin{array}{l}\text { Áp lực đất gây chuyển vị tường vây làm lượng lớn } \\
\text { bề mặt đất bị sụt lún gây mất ổn định các công } \\
\text { trình lân cận }\end{array}$ & 4,36 \\
\hline 4 & $\begin{array}{l}\text { Kết quả khảo sát bị sai lệch, kết quả khảo sát có } \\
\text { tính phân tán lớn do địa chất biến đồi trong phạm } \\
\text { vi khá rộng, không đồng đều }\end{array}$ & 4,36 \\
\hline 5 & $\begin{array}{l}\text { Mâu thuẩn với điều kiện địa chất trong quá trình } \\
\text { tính toán so với thực tế }\end{array}$ & 4,36 \\
\hline 6 & $\begin{array}{l}\text { Hạn chế về năng lực xây dựng của nhà thầu về kinh } \\
\text { nghiệm, máy móc, nhân lực }\end{array}$ & 4,33 \\
\hline 7 & $\begin{array}{l}\text { Khống chế mực nước ngầm, hạ mực nước ngầm } \\
\text { trong phạm vi rộng, không hợp lý sẽ gây lún cho }\end{array}$ & 4,30 \\
\hline
\end{tabular}

\begin{tabular}{|c|c|c|}
\hline Hạng & Nhân tố rủi ro & $\begin{array}{l}\text { Trung } \\
\text { bình }\end{array}$ \\
\hline & các công trình lân cận & \\
\hline 8 & $\begin{array}{l}\text { Máy bơm vữa xi măng đất có áp lực bơm không } \\
\text { đạt yêu cầu dẫn đến việc xử lý khe hở tường vây } \\
\text { hoặc gia cố nền không đạt yêu cầu kỹ thuật }\end{array}$ & 4,30 \\
\hline 9 & $\begin{array}{l}\text { Không có sự thống nhất giữa các bản vẽ thiết kế và } \\
\text { các hồ sơ khác như Spec, Scop }\end{array}$ & 4,29 \\
\hline 10 & Sự thiếu trách nhiệm của các cá nhân tham gia dự án & 4,28 \\
\hline 11 & $\begin{array}{l}\text { Thiếu sự trao đổi, phối hợp giữa các bên tham gia } \\
\text { dự án }\end{array}$ & 4,17 \\
\hline 12 & $\begin{array}{l}\text { Sự bất khả kháng như thiên tai, mưa bão làm sạt lỡ } \\
\text { hố đào dẫn đến làm chuyển dịch tường chắn }\end{array}$ & 4,13 \\
\hline 13 & $\begin{array}{l}\text { Các giải pháp chống thấm của tường Barrette, đặc } \\
\text { thù là xử lý mối nối giữa các panels chưa đạt được } \\
\text { hiệu quả }\end{array}$ & 4,12 \\
\hline 14 & $\begin{array}{l}\text { Hệ thống sử dụng dung dịch Bentonite không đáp } \\
\text { ứng được yêu cầu, không xử lý hết cặn bả, dẫn đến } \\
\text { Bentonite không đảm bảo các thông số kỹ thuật dẫn } \\
\text { đến sập thành hố khoan }\end{array}$ & 4,10 \\
\hline 15 & $\begin{array}{l}\text { Thiếu sự quan trắc thường xuyên công trình trong } \\
\text { quá trình thi công nên không phát hiện sự cố để xử } \\
\text { lý kịp thời }\end{array}$ & 4,08 \\
\hline 16 & $\begin{array}{l}\text { Chiều sâu và chiều rộng hố đào càng lớn thì gây ra } \\
\text { chuyển vị tường vây càng lớn }\end{array}$ & 4,07 \\
\hline 17 & $\begin{array}{l}\text { Chú trọng đến tiến độ thời gian thi công nhanh, bỏ } \\
\text { bớt công đoạn thi công gây ảnh hưởng đến chuyển } \\
\text { vị tường vây }\end{array}$ & 4,05 \\
\hline 18 & $\begin{array}{l}\text { Độ cứng hệ chống giữ ảnh hưởng đến chuyển vị } \\
\text { tường vây }\end{array}$ & 4,05 \\
\hline 19 & $\begin{array}{l}\text { Không xác định rõ phạm vi và trách nhiệm công } \\
\text { việc cho từng cá nhân, đơn vị khi thi công }\end{array}$ & 4,04 \\
\hline 20 & $\begin{array}{l}\text { Lựa chọn kích thước các Panel không hợp lý đối } \\
\text { với tường vây Barrette }\end{array}$ & 4,04 \\
\hline 21 & $\begin{array}{l}\text { Vị trí, kích thước lỗ mở sàn không hợp lý làm độ } \\
\text { cứng của sàn theo phương ngang sẽ bị giảm yếu rất } \\
\text { nhiều do làm tăng chuyển vị tường vây }\end{array}$ & 4,04 \\
\hline 22 & $\begin{array}{l}\text { Tổ hợp các thiết bị đo đạc như máy kinh vĩ, toàn } \\
\text { đạc bị lỗi dẫn đến sai số trong công tác định vị }\end{array}$ & 4,04 \\
\hline 23 & Công tác tiện ích cho công trường không đạt yêu cầu & 4,02 \\
\hline 24 & $\begin{array}{l}\text { Tổ hợp máy thi công sử dụng cũ kỹ lạc hậu, không } \\
\text { đáp ứng yêu cầu thi công, không phù hợp với điều } \\
\text { kiện địa chất }\end{array}$ & 4,01 \\
\hline 25 & $\begin{array}{l}\text { Sự chủ quan dựa vào kinh nghiệm, không tương } \\
\text { ứng hoặc không phù hợp với công nghệ mới }\end{array}$ & 4,01 \\
\hline 26 & Quá trình thi công rung ép, rút cừ bị chấn động & 4,01 \\
\hline 27 & $\begin{array}{l}\text { Công nhân có tay nghề chuyên môn thi công tường } \\
\text { vây còn yếu }\end{array}$ & 3,98 \\
\hline
\end{tabular}




\begin{tabular}{|c|c|c|}
\hline Hạng & Nhân tố rủi ro & $\begin{array}{l}\text { Trung } \\
\text { bình }\end{array}$ \\
\hline 28 & $\begin{array}{l}\text { Bê tông tường vây không đạt chất lượng có nhiều } \\
\text { tổ ong gây thấm tường vây }\end{array}$ & 3,98 \\
\hline 29 & $\begin{array}{l}\text { Hạn chế về năng lực của nhà thầu trong công việc } \\
\text { bố trí mặt bằng thi công trong công trường }\end{array}$ & 3,94 \\
\hline 30 & $\begin{array}{l}\text { Biến dạng đất nền rất phức tạp do xuất hiện những } \\
\text { công trình hiện hữu lân cận, mực nước ngầm và áp } \\
\text { lực đất }\end{array}$ & 3,93 \\
\hline 31 & $\begin{array}{l}\text { Liên kết giữa các tấm cừ kém làm cho cừ không } \\
\text { liên tục, có khe hở lớn }\end{array}$ & 3,75 \\
\hline 32 & $\begin{array}{l}\text { Dung dịch Bentonite giữ thành vách hố đào không } \\
\text { đạt chất lượng do giám sát không chặt chẽ trong } \\
\text { quá trình thi công để đảm bảo các chỉ tiêu cần thiết }\end{array}$ & 3,68 \\
\hline 33 & $\begin{array}{l}\text { Vật liệu thi công không đúng chỉ tiêu kỹ thuật và } \\
\text { quy trình công nghệ như gioằng chống thấm, bê } \\
\text { tông, cốt thép }\end{array}$ & 3,68 \\
\hline 34 & $\begin{array}{l}\text { Bê tông tường vây bị khuyết tật lại do cát chảy gây } \\
\text { lún/nứt/sập công trình lân cận }\end{array}$ & 3,64 \\
\hline 35 & $\begin{array}{l}\text { Điều kiện đất yếu, mực nước ngầm dâng cao gây trượt } \\
\text { lở đất, mất ổn định hố đào gây chuyển vị tường vây }\end{array}$ & 3,62 \\
\hline 36 & $\begin{array}{l}\text { Thiếu tiêu chuẩn quản lý chất lượng, tiêu chuẩn thi } \\
\text { công và nghiệm thu tường vây Barrette }\end{array}$ & 3,57 \\
\hline 37 & $\begin{array}{l}\text { Bề dày sàn , giảm bề dày sàn làm giảm độ cứng của } \\
\text { sàn trong mặt phẳng làm tăng chuyển vị tường vây }\end{array}$ & 3,53 \\
\hline
\end{tabular}

Từ 37 nhân tố rủi ro được xác định theo bảng trên, thông qua phân tích nhân tố để rút gọn các nhân tố và tìm ra những nhân tố rủi ro chính tác động đến sự thành công của dự án tường vây, tường chắn đất trong các dự án xây dựng ở Việt Nam. Kết quả của phân tích nhân tố cụ thể được trình bày trong Bảng 2.

\section{Bảng 2.}

Kết quả phân tích nhân tố.

\begin{tabular}{|c|c|c|c|c|}
\hline & Nhân tố rủi ro & $\begin{array}{l}\text { Factor } \\
\text { Loading }\end{array}$ & $\begin{array}{l}\text { Eigen- } \\
\text { values }\end{array}$ & $\begin{array}{c}\text { \% } \\
\text { Phương } \\
\text { sai trích }\end{array}$ \\
\hline \multirow[b]{3}{*}{$\begin{array}{l}\text { Khiếm } \\
\text { khuyết }\end{array}$} & $\begin{array}{l}\text { Vật liệu thi công không } \\
\text { đúng chỉ tiêu kỹ thuật và } \\
\text { quy trình công nghệ như } \\
\text { gioằng chống thấm, bê } \\
\text { tông, cốt thép }\end{array}$ & 0,79 & & \\
\hline & $\begin{array}{l}\text { Liên kết giữa các tấm cừ } \\
\text { kém làm cho cừ không liên } \\
\text { tục, có khe hở lớn }\end{array}$ & 0,76 & & \\
\hline & $\begin{array}{l}\text { Thiếu tiêu chuẩn quản lý } \\
\text { chất lượng, tiêu chuẩn thi } \\
\text { công và nghiệm thu tường } \\
\text { vây Barrette }\end{array}$ & 0,70 & 6,53 & 13,73 \\
\hline
\end{tabular}

\begin{tabular}{|c|c|c|c|c|}
\hline & Nhân tố rủi ro & $\begin{array}{r}\text { Factor } \\
\text { Loading }\end{array}$ & $\begin{array}{l}\text { Eigen- } \\
\text { values }\end{array}$ & $\begin{array}{c}\text { \% } \\
\text { Phương } \\
\text { sai trích }\end{array}$ \\
\hline \multirow[t]{3}{*}{ vật liệu } & $\begin{array}{l}\text { Các giải pháp chống thấm } \\
\text { của tường Barrette, đặc } \\
\text { thù là xử lý mối nối giữaa } \\
\text { các panels chưa đạt được } \\
\text { hiệu quả }\end{array}$ & 0,67 & & \\
\hline & $\begin{array}{l}\text { Dung dịch Bentonite giữ } \\
\text { thành vách hố đào không } \\
\text { đạt chất lượng do giám sát } \\
\text { không chặt chẽ trong quá } \\
\text { trình thi công để đảm bảo } \\
\text { các chỉ tiêu cần thiết }\end{array}$ & 0,66 & & \\
\hline & $\begin{array}{l}\text { Sự bất khả kháng như } \\
\text { thiên tai, mưa bão làm sạt } \\
\text { lỡ hố đào dẫn đến làm } \\
\text { chuyển dịch tường chắn }\end{array}$ & 0,66 & & \\
\hline \multirow{5}{*}{$\begin{array}{l}\text { Máy móc } \\
\text { và xung } \\
\text { đột trong } \\
\text { quá trình } \\
\text { thi công }\end{array}$} & $\begin{array}{l}\text { Tổ hợp máy thi công sử } \\
\text { dụng cũ kỹ lạc hậu, không } \\
\text { đáp ứng yêu cầu thi công, } \\
\text { không phù hợp với điều } \\
\text { kiện địa chất }\end{array}$ & 0,81 & \multirow{5}{*}{2,03} & \multirow{5}{*}{11,47} \\
\hline & $\begin{array}{l}\text { Không có sự thống nhất } \\
\text { giữa các bản vẽ thiết kế và } \\
\text { các hồ sơ khác như Spec, } \\
\text { Scop }\end{array}$ & 0,73 & & \\
\hline & $\begin{array}{l}\text { Tổ hợp các thiết bị đo đạc } \\
\text { như máy kinh vĩ, toàn đạc } \\
\text { bị lỗi dẫn đến sai số trong } \\
\text { công tác định vị }\end{array}$ & 0,71 & & \\
\hline & $\begin{array}{l}\text { Mâu thuẩn với điều kiện } \\
\text { địa chất trong quá trình } \\
\text { tính toán so với thực tế }\end{array}$ & 0,69 & & \\
\hline & $\begin{array}{l}\text { Máy bơm vữa xi măng đất } \\
\text { có áp lực bơm không đạt } \\
\text { yêu cầu dẫn đến việc xử lý } \\
\text { khe hở tường vây hoặc gia } \\
\text { cố nền không đạt yêu cầu } \\
\text { kỹ thuật }\end{array}$ & 0,66 & & \\
\hline \multirow[b]{2}{*}{$\begin{array}{l}\text { Năng lực } \\
\text { các bên } \\
\text { tham gia } \\
\text { dự án }\end{array}$} & $\begin{array}{l}\text { Kết quả khảo sát bị sai lệch, } \\
\text { kết quả khảo sát có tính } \\
\text { phân tán lớn do địa chất } \\
\text { biến đổi trong phạm vi khá } \\
\text { rộng, không đồng đều }\end{array}$ & 0,86 & & \\
\hline & $\begin{array}{l}\text { Hạn chế về năng lực của } \\
\text { đội ngũ cán bộ như ban } \\
\text { quản lý dự án, tư vấn, nhà } \\
\text { thầu về biện pháp thi công } \\
\text { tường vây }\end{array}$ & 0,78 & 1,93 & 9,54 \\
\hline
\end{tabular}




\begin{tabular}{|c|c|c|c|c|}
\hline & Nhân tố rủi ro & $\begin{array}{r}\text { Factor } \\
\text { Loading }\end{array}$ & $\begin{array}{l}\text { Eigen- } \\
\text { values }\end{array}$ & $\begin{array}{c}\text { \% } \\
\text { Phương } \\
\text { sai trích }\end{array}$ \\
\hline & $\begin{array}{l}\text { Phương án thiết kế tường } \\
\text { vây không hợp lý }\end{array}$ & 0,68 & & \\
\hline & $\begin{array}{l}\text { Thiếu sự trao đổi, phối hợp } \\
\text { giữa các bên tham gia dự án }\end{array}$ & 0,46 & & \\
\hline \multirow{4}{*}{$\begin{array}{l}\text { Kỹ thuật } \\
\text { và biện } \\
\text { pháp thi } \\
\text { công }\end{array}$} & $\begin{array}{l}\text { Thiếu sự quan trắc thường } \\
\text { xuyên công trình trong } \\
\text { quá trình thi công nên } \\
\text { không phát hiện sự cố để } \\
\text { xử lý kịp thời }\end{array}$ & 0,80 & \multirow{4}{*}{1,77} & \multirow{4}{*}{9,13} \\
\hline & $\begin{array}{l}\text { Chú trọng đến tiến độ thời } \\
\text { gian thi công nhanh, bỏ bớt } \\
\text { công đoạn thi công gây ảnh } \\
\text { hưởng đến chuyển vị } \\
\text { tường vây }\end{array}$ & 0,78 & & \\
\hline & $\begin{array}{l}\text { Khống chế mực nước ngầm, } \\
\text { hạ mực nước ngầm trong } \\
\text { phạm vi rộng, không hợp lý } \\
\text { sẽ gây lún cho các công trình } \\
\text { lân cận }\end{array}$ & 0,69 & & \\
\hline & $\begin{array}{l}\text { Hạn chế về năng lực xây } \\
\text { dựng của nhà thầu về kinh } \\
\text { nghiệm, máy móc, nhân lực }\end{array}$ & 0,59 & & \\
\hline \multirow{7}{*}{ Thiết kế } & $\begin{array}{l}\text { Độ cứng hệ chống giữ ảnh } \\
\text { hưởng đến chuyển vị } \\
\text { tường vây }\end{array}$ & 0,79 & \multirow{4}{*}{1,58} & \multirow{4}{*}{8,91} \\
\hline & $\begin{array}{l}\text { Hệ thống sử dụng dung } \\
\text { dịch Bentonite không đáp } \\
\text { ứng được yêu cầu, không } \\
\text { xử lý hết cặn bả, dẫn đến } \\
\text { Bentonite không đảm bảo } \\
\text { các thông số kỹ thuật dẫn } \\
\text { đến sập thành hố khoan }\end{array}$ & 0,72 & & \\
\hline & $\begin{array}{l}\text { Lựa chọn kích thước các } \\
\text { Panel không hợp lý đối với } \\
\text { tường vây Barrette }\end{array}$ & 0,70 & & \\
\hline & & & & \\
\hline & $\begin{array}{l}\text { Công tác tiện ích cho công } \\
\text { trường không đạt yêu cầu }\end{array}$ & 0,78 & & \\
\hline & $\begin{array}{l}\text { Bề dày sàn, giảm bề dày sàn } \\
\text { làm giảm độ cứng của sàn } \\
\text { trong mặt phẳng làm tăng } \\
\text { chuyển vị tường vây }\end{array}$ & 0,78 & & \\
\hline & $\begin{array}{l}\text { Vị trí, kích thước lỗ mở sàn } \\
\text { không hợp lý làm độ cứng } \\
\text { của sàn theo phương ngang } \\
\text { sẽ bị giảm yếu rất nhiều do }\end{array}$ & 0,73 & 1,35 & 7,97 \\
\hline
\end{tabular}

\begin{tabular}{|c|c|c|c|c|}
\hline & Nhân tố rủi ro & $\begin{array}{c}\text { Factor } \\
\text { Loading }\end{array}$ & $\begin{array}{l}\text { Eigen- } \\
\text { values }\end{array}$ & $\begin{array}{c}\% \\
\text { Phương } \\
\text { sai trích }\end{array}$ \\
\hline $\begin{array}{l}\text { Biện pháp } \\
\text { thi công } \\
\text { liên quan } \\
\text { đến sàn }\end{array}$ & làm tăng chuyển vị tường vây & & & \\
\hline
\end{tabular}

\section{Thảo luận kết quả}

Kết quả nghiên cứu cho thấy nhóm nhân tố Khiếm khuyết vật liệu là nhóm nhân tố rủi ro nhất. Thật vậy, nhân tố từ việc khiếm khuyết vật liệu có ảnh hưởng nhất trong việc giải thích 13,73 \% sự biến thiên của dữ liệu. Từ kết quả này, có thể nhận định rằng vai trò của các bên tham gia dự án trong việc giám sát các qui định, tiêu chuẩn, qui phạm kỹ thuật đóng vai trò quyết định đến hiệu quả và chất lượng tường vây, tường chắn đất. Thêm nữa, cũng cần có những qui định rõ ràng về quyền hạn, nghĩa vụ của các bên trong quá trình đầu tư xây dựng từ khâu thiết kế, thi công, giám sát, nghiệm thu, bảo hành, sử dụng công trình...

Nhóm nhân tố tiếp theo là nhân tố Máy móc và sự xung đột trong quá trình thi công đóng vai trò ảnh hưởng thứ hai qua việc giải thích với 11,47 \% sự biến thiên của dữ liệu. Những năm gần đây các thiết bị máy móc tiên tiến hiện đại được sử dụng rất nhiều trong các công trình xây dựng, có những máy móc thiết bị do không đáp ứng các tiêu chuẩn an toàn khi sử dụng và phải chờ thời gian để sửa chữa, khắc phục, thậm chí nhiều máy móc thiết bị không được phép đưa vào công trường phải thay thế bằng máy móc thiết bị khác. Đây cũng là nguyên nhân gây ra chậm tiến độ thi công làm ảnh hưởng đến lợi nhuận của các doanh nghiệp. Tất cả máy móc, thiết bị trên công trường phải đảm bảo luôn đáp ứng yêu cầu về an toàn và chất lượng.

Nhóm nhân tố tiếp theo là nhân tố Năng lực các bên tham gia dự án được đánh giá mức độ tác động xếp thứ ba với giá trị giải thích sự biến thiên dữ liệu là 9,54\%. Năng lực của các bên tham gia dự án là sự tất yếu cho sự thành công của các dự án xây dựng nói chung và các dự án phức tạp tầng hầm, tường vây, tường chắn đất nói riêng.

Nhóm nhân tố tiếp theo là nhân tố Kỹ thuật thi công và biện pháp thi công cũng là một trong những nhân tố chính, giải thích 9,13\% sự biến thiên của dữ liệu. Khi thi công tầng hầm cho các công trình nhà cao tầng, một vấn đề phức tạp đặt ra là biện pháp, kỹ thuật thi công hố đào sâu trong khu đất chật hẹp. Thi công hố đào sâu làm thay đổi trạng thái ứng suất, biến dạng trong đất nền xung quanh khu vực hố đào và có thể làm thay đổi mực nước ngầm dẫn đến nền đất bị dịch chuyển và có thể lún gây hư hỏng công trình lân cận nếu không có giải pháp thích hợp.

Nhóm nhân tố tiếp theo là nhân tố Thiết kế là nhân tố chính xếp thứ năm, giải thích đến $8,91 \%$ biến thiên dữ liệu. Tường vây tầng hầm là dạng kết cấu phổ biến trong các công trình dân dụng, là dạng kết cấu được tính toán dựa trên sự kết hợp chặt chẽ giữa bài toán nền 
móng và bài toán kết cấu công trình. Giải pháp thiết kế và thi công tầng hầm nhà cao tầng gắn bó chặt chẽ với nhau do đặc điểm thiết kế kết cấu chắn giữ công trình tầng hầm phụ thuộc vào công nghệ thi công. Kết cấu chắn giữ có thể đồng thời là kết cấu chịu lực vĩnh cửu cho công trình. Do đó giải pháp thi công tổng thể cần được lựa chọn ngay từ khâu thiết kế công trình.

Nhóm nhân tố cuối là nhân tố Biện pháp thi công liên quan đến sàn là một nhân tố sau cùng trong nhóm sáu nhân tố được xác định, giải thích được 7,97 \% sự biến thiên của dữ liệu. Lố mở sàn thường được sử dụng để tạo lỗ chờ cho thiết bị điện nước công trình hoặc phục vụ biện pháp thi công, dựa vào vai trò chúng ta sẽ tập trung vào hai loại: lỗ mở kỹ thuật: $\mathrm{ME}$, thiết bị, lỗ biện pháp: trắc đạc, vận chuyển, đặt chờ,.... Bề dày sàn và lỗ mở sàn đều ảnh hưởng sự chuyển vị của tường vây.

\section{Kết luận}

Bài báo này đã xác định được 37 nhân tố rủi ro tác động đến chất lượng tường vây, tường chắn đất của các dự án nhà cao tầng có phần ngầm ở Việt Nam, được chia làm 6 nhóm nhân tố như sau: (1) các nhân tố Khiếm khuyết vật liệu, (2) các nhân tố Máy móc và sự xung đột trong quá trình thi công (3) các nhân tố Năng lực các bên tham gia dự án, (4) các nhân tố Kỹ thuật thi công và biện pháp thi công, (5) các nhân tố Thiết kế, (6) các nhân tố Biện pháp thi công. Dựa trên kết quả nghiên cứu, nhà quản lý dự án có thể thấy được những nguyên nhân chủ yếu của các dự án hiện nay và đề xuất các ứng phó phù hợp.

\section{Tài liệu tham khảo}

[1]. Lê Hoàng Việt (2013). Tổng quan về Thiết kê - Thi công hố đào sâu công trình ngầm, Khoa Học Công Nghệ.

[2]. Nguyễn Bá Kế (2010). Bài học từ sự cố sập đổ viện Khoa Học Xã hội vùng Nam bộ ở thành phố Hồ Chí Minh, Viện Khoa Học Công Nghệ Xây Dựng.

[3]. TCVN ISO 31000:2018, Quản lý rủi ro - hướng dẫn, Bộ Khoa học và công nghệ, Việt Nam.

[4]. Nguyễn Văn Châu (2013), Tổng quan các công trình nghiên cứu về rủi ro và QLRR trong dự án XDCT đường bộ, Báo cáo chuyên đề nghiên cứu sinh, Trường đại học GTVT Hà Nội.

[5]. PMI (2019), The Standard for Risk Management in Portfolios, Programs, and Projects.

[6]. Hair \& ctg (2009), Multivariate Data Analysis, 7th Edition.

[7]. Hoàng Trọng và Chu Nguyễn Mộng Ngọc (2008). Phân tích dữ liệu nghiên cứu với SPSS, Nhà xuất bản Hồng Đức, Đại học Kinh tế Thành phố Hồ Chí Minh, Tập 1 và Tập 2.

[8]. Nguyễn Đình Thọ (2016), Phương pháp nghiên cứu khoa học trong kinh doanh, NXB Tài Chính, Tái bản lần 2.

[9]. Đỗ Công Hoan (2020). Xây dựng ảnh tiêu chí lựa chọn đơn vị thi công tường vây và khoan nhồi cho các dự án cao tầng tại thành phố Hồ Chí Minh. Luận văn cao học ngành QLXD, Đại học Bách Khoa, TP HCM.

[10]. Đàm Lê Minh Thông (2015). Các yếu tố rủi ro trong quá trình thi công phần ngầm nhà cao tầng áp dụng cho các công trình tại thành phố Hồ Chí Minh. Luận văn cao học, Đại học Công Nghệ, TP HCM.

[11]. Nguyễn Minh Trực (2011). Quản lý rủi ro trong quá trình thi công tầng hầm ở các dự án nhà cao tầng. Luận văn cao học ngành QLXD, Đại học Bách Khoa, TP HCM. 